8 Sasieni P, Adams J, Cuzick J. Benefit of cervical screening at different ages: evidence from the UK audit of screening histories. Br J Cancer 2003; 89: 88-93.

9 Sasieni P, Castanon A, Parkin DM. How many cervical cancers are prevented by treatment of screen-detected disease in young women? Int J Cancer 2009; 124: 461-464.

10 Sigurdsson K, Sigvaldason H. Is it rational to start populationbased cervical cancer screening at or soon after age 20 ?
Analysis of time trends in pre-invasive and invasive diseases. Eur J Cancer 2007; 43: 769-774.

11 Herbert A, Holdsworth G, Kubba A. Cervical screening: why young women should be encouraged to be screened. J Fam Plann Reprod Health Care 2008; 34: 21-25.

12 Wellings K, Nanchahal K, Macdowall W, McManus S, Erens B, Mercer $\mathrm{CH}$, et al. Sexual behaviour in Britain: early heterosexual experience. Lancet 2001; 358: 1843-1850.

\title{
What a load of rankers
}

\section{Sue Perankin}

So very soon anyone who can access the Internet will be able to leave a defamatory remark about me, thanks to the latest stage of the Government's ongoing GP-bashing campaign, or "we're out to get you" as I like to call it. Under the guise of choice (how I hate that word), patients will be able to log on to the NHS Choices website and say what they think of GPs like me. Some choice, because once it's up there it's going to be impossible to get rid of it, or for me to explain the truth which is, for example: "No, the reason why I refused to give you a pregnancy test was because you've had a hysterectomy, and they removed your ovaries, and you told me you'd not even been in the same room as a man for 5 years, and because I had a bloody good look out of the window and there was no bright light, and neither were there any shepherds or wise men in the waiting room". What a nightmare.

Why do we need this? We don't, is the short, and honest, answer. Survey after survey reports how good we are in our patients' eyes. And therein lays the nub. How can the Government's agenda to bash GPs be fulfilled if the public keeps on saying we're so wonderful? Anyone who bashes GPs shoots themselves in the foot because doing so backfires on them. "How dare you say that about my wonderful doctor, you nasty politician you. I'll not vote for you again." So how do you turn people? You infiltrate, or start a smear campaign.

This whim provides an opportunity for free speech the choice to say something - whilst driving traffic through the NHS website. It's a perfect plan for our taskmasters' aims. Moreover, it's foolproof because it's so one-sided. Rules of patient confidentiality prevent us from giving the facts and defending ourselves, from giving our side of the story. For instance being able to say: "Actually, I didn't call her a slag. What I said was that she appears to be coming in to see me on a monthly basis wanting to be tested for sexually transmitted diseases, so perhaps she should think about using condoms in the future". Then there are the more difficult and career-threatening misinterpretations because of language or accent: "I would never use that word. What I was trying to explain was that under the circumstances there are things that need to be done you can't face".

It's so perverse, and not in a "Oh, that feels so good. I've always wanted to try this" kind of way. Comments posted on the website could sully my reputation, leaving me viewed as an uncaring bastard, it's true. But the knock-

J Fam Plann Reprod Health Care 2009; 35(2): 120

Chartswell Surgery, Bloughinham, UK

Sue Perankin, MRCGP, General Practitioner on effect of this will be the undermining of a patient's confidence in me, a GP who in their eyes had always done very well by them as practice surveys have confirmed annually. In turn the burden of additional stress will make the previously well and happy patient sick, and the unwell patient sicker. End result: a Government plan that makes people sick and adds further pressure on an already drowning NHS. Brilliant.

I'm trying to see a positive to this latest wheeze that isn't more than our paymasters feebly trying to find something to justify not giving the NHS IT system a oneway ticket to Switzerland. Logically you'd think that if a patient believed their GP was dreadful, they'd change GP. But they don't, do they? They stay and make our lives even more miserable. Conversely, I could be swamped with eager gift-bearing patients who want to be looked after by the "so caring and considerate" doctor listed on the site, so every cloud and all that.

I can always dream but why are we surprised when we get a thank you from our patients, because we're more used to getting a complaint. Go to a group or public meeting and what happens? The people with an axe to grind are those who come along. Set up a support group and it's moaners who join. Set up a facility to rank and leave comments about your GP and you don't need me to tell you who are most likely people to leave a comment and what the tone of that comment might be.

Oh heck, I need something to ensure I get a good NHS Choices rating - after all, I am a star. I think I have just the ticket. It's time to return to the old days, the Dr Kildare days, that many people think is current practice, because general practice is still portrayed like this in modern medical TV dramas. That means going back to unnecessary home visits to drop off information leaflets and to deliver appointment details in person, cold phone calling just to "make sure you are OK", and the true art of medicine, which of course is all tea, sympathy and bluff.

Nowadays you can't assume it's only young people who'll use this facility because the older population use the Internet too. I guess I'll need to convince my patients that the Internet is a nasty sex-promoting thing where anyone can say whatever they like, and that you shouldn't believe what's on it, so their stock response becomes: "Oh, I don't believe what they say about you. You've always been wonderful to me". To which I'll reply: "I expect you'll be needing another prescription for lorazepam then? And, perhaps you'd like to write what you just said here in this box on the screen for me? Thank you, that's perfect. What's it all about? Oh, it's just some new thing they want us to do, you know how it is, about ranking us. So I want to make sure I have a good rank."

"That's disgraceful, doctor." "Yes, it is, isn't it?" 